\title{
Editorial
}

\section{Patient power, human rights and access to primary health care services in an NHS system}

A central theme of contemporary primary health care in England is patient power - the power of the patient to make real choices both as to who provides the service and to the nature of treatment. Patient power is of particular relevance in the context of a National Health Service which has traditionally tied patients to the GP practice in which they were registered, such that shopping around for alternative providers who might be prepared to offer alternative treatments was difficult, if not impossible. Funded health systems predicated on reimbursement of costs, as is the case in much of the rest of Europe and in Australia, and the provision of primary health care services in the private sector across the world, have always allowed significantly greater patient choice.

Recognition of the patient's right to choose is not a one-way process. There is a corollary to choice - the obligation on providers to respect that choice. This means that, 'The NHS will have to share a great deal of knowledge with patients, users and carers so that they are informed and better equipped to use that knowledge', bearing in mind that there is 'evidence that direct involvement of the patient in the selection of their medication leads to benefits' (Secretary of State, 2003). The recognition of the patient as a stakeholder rather than a grateful recipient in the provision of health care services is a new approach within English National Health Service philosophy. The NHS has until now been based on 'a paternalistic model of decision-making' (Department of Health, 2001). Recognizing patient choice will require adjustment to both the process and the environment of health delivery.
This will be even more the case where services are provided in such a way that those "most at risk of ill-health also tend to experience the least satisfactory access to a full range of preventing services' (Department of Health, 2002). There is evidence of discrimination on grounds of age within both primary and secondary health care (Gulland, 2003; Kmietowicz, 2001; Macdonald, 2003; Tonks, 1999). Patients with learning disabilities are disadvantaged in access to services such as cervical screening (Aspray et al., 1999; Pearson et al., 1998), and patients with Down's Syndrome are disadvantaged in access to lifesaving surgery (Leonard et al., 2000; Mayor, 1999). The Government White Paper on disability (Secretary of State for Health, 2001) recognizes that mortality rates are higher for persons with learning disabilities because of disadvantaged access, and suggests that primary care teams should play a key role in supporting improved access to health care.

Enabling real power in relation to patient access to health services will inevitably create tensions in a system which has always retained total control of the distribution of health goods. Patient power will be sorely tested where the provider considers the chosen medicine or treatment to be unsuitable, unavailable or too expensive, when health care policy inhibits access to services the patient wants or needs, or when patients demand access to individual practitioners whose patient lists are already overflowing. English law has until now been reluctant to interfere with decisions on access to health care, but the Human Rights Act may enable patients to use human rights arguments to enforce the exercise of patient power. 


\section{The Human Rights Act 1998}

The Human Rights Act 1998 introduces into English domestic law rights recognized by the European Convention for the Protection of Human Rights and Fundamental Freedoms, and imposes obligations on public authorities to act in accordance with those rights. Primary health care trusts are public authorities, and a PCT will be vicariously liable for an employee, including a salaried GP, acting on its behalf if the employee behaves in a way which breaches a patient's rights. A PCT will also be legally accountable for GP practice where GPs are on a GMS contract, if responsibility for the management of services, determination of policy, allocation of primary health care resources and handling of patent complaints lies with the PCT. The Human Rights Act serves to protect patients, potential patients and families of patients from any unlawful interference with rights.

The Act has created new statutory causes of action, and a victim of a breach of rights can bring a claim under the Act for damages for any resulting harm. In addition the jurisprudence of human rights has affected the way in which the action in negligence and the traditional English action for judicial review are decided. Recognition of rights has prompted judges to look more closely at professional common practice within professions which have previously been accorded some immunity from judicial scrutiny. This means that English courts will be less reluctant to scrutinize the clinical and policy judgements of health providers.

\section{Challenging treatment decisions and policies within primary health care}

Human rights arguments will particularly assist those seeking judicial review of an act, decision or policy of a PCT. Judicial review has long been used as a means of challenge of health care decisions in English law, but prior to the Human Rights Act challenges were mostly unsuccessful. The claimant needed to establish that the treatment decision was so irrational that no other similar body could have reached the same decision (Associated Provincial Picture Houses, 1948), and courts were rarely prepared to recog- nize such a degree of irrationality. In a case in which a health authority refused, for reasons of staff shortage, to carry out urgent heart surgery on a baby in immediate danger, the court would have been prepared to intervene only if no other health authority could have decided in the same way (Collier, 1988). Similarly the court refused to interfere with the decision of the Cambridge Area Health Authority not to provide further cancer treatment to Jamie B (Re B, 1995).

Article 2 of the Convention, which recognizes that everyone's right to life will be protected by law, will now make it more difficult for a health authority to defend refusal of reasonably available resources to save life, and even more difficult to defend general policies which restrict access to life-saving resources. The first suggestion of a more rights based approach was seen in an action against a health authority which had as a matter of policy refused to offer the drug beta-interferon to a patient with multiple sclerosis (Fisher, 1998). The patient successfully sought judicial review of that policy, and the court held that a health authority had an obligation to follow national guidelines on provision of medical services. Where the authority wished to depart from national guidance it needed to give clear reasons for departure.

In $R v$ North West Lancashire Health Authority 1999 three transsexuals successfully challenged health authority policy not to offer surgery after having accepted that general identity dysphoria was a medical illness. Because this was a blanket policy against provision of surgery, each patient would not be considered on the basis of individual medical profile and this was found to be irrational. The court held that a policy decision to give low priority to particular types of treatments had to be clear, transparent and subject to exception in cases of overriding clinical need. A patient suffering from asthma successfully challenged her needs assessment on the basis that failure to take into account particular personal circumstances made the assessment irrational, despite evidence that shortage of resources would make it difficult to give the patient the support she was seeking (Maali, 2003). It is clear that a more sympathetic legal understanding of irrationality is developing which will enable patients to challenge more easily decisions and policies which fail to take account of the needs and expectations of the particular patient. 
Not all post-Human Rights Act challenges of health policy or treatment have succeeded. A challenge to the re-organization of cancer services in East Kent (Smith, 2002) failed because the trust had properly consulted before making the changes. An attempt to challenge arrangements made for a patient with Asperger's Syndrome failed because the decision was made after a careful assessment of the patient's needs and so was not irrational (Rodriguez-Bannister, 2003).

What the case law since the Human Rights Act does suggest is that English courts will be more willing to hear challenges of health decisions. Policies and decisions which are made without deliberation, which contravene national guidelines, which are not clear and transparent and subject to exception in cases of overriding need, will be particularly vulnerable. Where treatment is necessary to save life, then regardless of the cost of the resource, the PCT will need to consider its obligation to protect the patient's right to life. Where the patient's condition is not life threatening the patient's choice of treatment need not be met, but the PCT will need to put in place protocols for determining how treatment decisions are to be made. The greater the government rhetoric about patient power, the greater the obligation on the PCT to include in its protocols justification for breaching the obligation to respect patient choice.

\section{Discrimination in access to primary health care services}

Article 14 of the Convention provides that an individual's enjoyment of Convention rights shall be secured without discrimination on any ground. This is wider than the protections offered against discrimination on the basis of sex, race and disability within domestic legislation. Article 14 will be of particular concern to health authorities given that some groups of patients are routinely disadvantaged in access to healthcare.

On the basis of guidelines recommended in the White Paper on disability, Article 14 could support legal action against PCTs which have failed to address access issues, especially where disadvantage in access could potentially threaten the right to life (Article 2), the right to private and family life (Article 8), or result in inhumane treatment of the patient (Article 3). Legal action could again take the form of judicial review of treatment policies, but might also give rise to actions in negligence where harm was suffered as a result of failure to facilitate access. If a patient were to die as a consequence of discrimination in access to treatments or medicines, then the patient's family might have an action on the basis of the Article 2 statutory duty to protect life, which would not require proof of negligence.

Discrimination in access has always breached the norms of health ethics, but there may now also be legal risk resulting from failure to take steps to remove obstacles to access. Increased government emphasis on reducing health inequalities within both medical services and public health provision serve only to strengthen the positive obligation on PCTs to provide equality of access, and will provide support for Article 14 challenges.

\section{Conclusion}

The importance of primary health care as the front line health care service makes it essential that primary health care services in England are delivered within a framework of human rights. The Human Rights Act, unlike English common law, is as much concerned with failure to protect rights as with positive acts in breach of rights. This imposes on PCTs an obligation to monitor and adjust all access practices and policies, and government documents purporting to recognize the power of the patient to choose will be evidence in the determination of rational decisionmaking. Failure to recognize Convention rights may result in legal risk, so it is essential that PCTs maintain as part of good practice an awareness of Convention rights, and of recognition by courts of rights based arguments, in the management of primary health care provision. Patient power should be no more problematic within an NHS system than it is in a system of health provision in which the patient is a paying client. There will always be resource constraints, and provided there is in place a system in which decisions are made according to clear, transparent, consistent and justifiable criteria, then failure 
to meet patient demand will withstand human rights challenge.

Robyn Martin,

Research Professor in Public Health Law, Centre for Research in Primary and Community Care,

University of Hertfordshire, College Lane, Hatfield, AL10 9AB,

$U K$

\section{References}

Aspray T.J., Francis, R.M., Tyrer, S. and Quilliam, P. 1999: Patients with learning disability in the community. British Medical Journal 318, 476.

Associated Provincial Picture Houses Ltd v Wednesbury Corp [1948] 1 KB 223.

Collier ( $R$ v Central Birmingham Health Authority, ex parte Collier) 6 January 1988, unreported.

Department of Health. 2001: Shifting the balance of power within the NHS: securing Delivery. London: The Stationary Office.

Department of Health. 2002: Addressing inequalities - reaching the hard to reach groups. London: The Stationary Office.

Fisher ( $R v$ North Derbyshire HA, ex parte Fisher) (1998) 38 BMLR 76.

Maali ( $R$ on the application of Maali $v$ Lambeth London Borough) 14 August 2003, unreported.
Gulland, A. 2003: Emergency centre aims to end age discrimination. British Medical Journal 327, 72.

Kmietowicz, Z. 2001: Plan to end age discrimination in NHS is launched. British Medical Journal 322, 751.

Leonard, H., Eastham, K. and Dark, J. 2000: Heart and lung transplantation in Down's syndrome. British Medical Journal 320, 816.

MacDonald, S. 2003: Age discrimination difficult o identify, says King's Fund guide. British Medical Journal 326, 355.

Mayor, S. 1999: Parents of people with Down's syndrome report suboptimal care. British Medical Journal 318, 687.

Pearson, V., Davis, C., Ruoff, C. and Dyer, J. 1998: Only one quarter of women with learning disability in exeter have cervical treatment. British Medical Journal 316, 1979.

$R v$ North West Lancashire Health Authority, ex parte A (1999) Lloyd's Rep. Med. 399.

Re B ( $R v$ Cambridge Area HA, ex parte B) (1995) 25 BMLR 5.

Rodriguez-Bannister ( $R$ on the application of RodriguezBannister $v$ Somerset Partnership NHS and Social Care Trust) 22 August 2003, unreported.

Secretary of State for Health. 2001: Valuing people: a new strategy for learning disability for the 21st Century. London: The Stationary Office.

Secretary of State. 2003: Equity, choice, capacity and culture. Speech by Rt Hon John Reid, 7 November 2003.

Smith ( $R v$ East Kent Hospital NHS Trust, ex parte Smith) 4 December 2002, unreported.

Tonks, A. 1999: Medicine must change to serve an aging society. British Medical Journal 319, 1450. 